\title{
Use of magnetic resonance imaging in the study of goat mammary glands in vivo*
}

\author{
P. A. Fowler†, C. H. Knight $\ddagger$, G. G. Cameron and M. A. Foster \\ Department of Bio-Medical Physics \& Bio-Engineering, University of Aberdeen, Aberdeen \\ $A B 92 Z D, U K$; and $\ddagger$ Hannah Research Institute, Ayr KA6 5HL, UK
}

\begin{abstract}
Summary. A technique is described for the in-vivo determination of mammary gland size and gross composition in goats by using nuclear magnetic resonance imaging (MRI). The volume of test objects determined with MRI had an error of $+0.4 \pm 1.6 \%$ of the actual volume. In lactating goats the in-vivo MRI estimate of mammary parenchymal volume was significantly greater than, but highly significantly correlated with, the weight of parenchyma determined post mortem (for the whole udder, $r=0.88$, $P<0.001$; for individual glands, $r=0.85, P<0.001$ ). MRI-determined estimates of the volume of fluid within the mammary gland were within $1.2 \%$ of the volume of milk removed from the udders after imaging. The spin-lattice $\left(T_{1}\right)$ relaxation time of the whole udder correlated closely with the volume of fluid within the udder. The $T_{1}$ relaxation time of parenchymal tissue measured in vivo did not differ significantly from that determined immediately after post-mortem excision.
\end{abstract}

Keywords: mammary gland; magnetic resonance imaging; methodology; goat; lactation

\section{Introduction}

Mammary development and function have been intensively investigated in laboratory species, but parallel studies in dairy animals, including goats, have been hampered by the lack of a suitably noninvasive technique for monitoring secretory tissue mass in vivo. Available methodologies such as water displacement and plaster casts (Linzell, 1966) determine only the gross external dimensions, and take no account of variation in internal composition. A well developed udder consisting of $80 \%$ secretory tissue and $20 \%$ stroma would be indistinguishable from another of the same size but containing $20 \%$ parenchyma and $80 \%$ stroma. For the same reason, water displacement cannot measure individual glands independently, when two or more are tightly juxtaposed, as in the udder of the goat.

Whole-body imaging techniques such as magnetic resonance imaging (MRI) and X-ray computed tomography (X-ray $\mathrm{CT}$ ) have the potential to provide information about gross internal composition of the gland, as well as its overall size. The ability of X-ray CT to discriminate between fatty stroma and ductal parenchyma has been demonstrated in heifers (Sejrsen et al., 1986; Sørensen et al., 1987), although these measurements were made in vitro on excised udders, since heifers are too big for conventional imagers. Preliminary studies suggested that goats could be studied in vivo using MRI (Foster \& Knight, 1983).

In MRI the hydrogen nuclei of water and lipid molecules are excited by electromagnetic radiation in the presence of a magnetic field, resulting in a detectable signal. The magnitude of the signal and the subsequent relaxation to the pre-excited state are measured. The use of magnetic field gradients allows this information to be collected from spatially defined parts of the body.

*Reprint requests to Dr C. H. Knight, Hannah Research Institute, Ayr KA6 5HL, UK.

$\Varangle$ Present address: Department of Obstetrics \& Gynaecology, University of Aberdeen, Aberdeen AB9 2ZD, UK. 
Water content varies between tissues and the water molecules have constraints upon their motion arising from hydration layers around larger molecules. The amount of water and lipid, and their freedom of motion, define signal size and NMR relaxation characteristics, such as the spin-lattice relaxation time $\left(T_{1}\right)$. This permits discrimination between tissues and the production of interpretable images of slices through the body (Hutchison et al., 1980; Foster \& Hutchison, 1985).

The aim of the present study was to determine the potential uses of MRI in the study of mammary tissue in vivo.

\section{Materials and Methods}

Animals. Lactating British Saanen goats, housed at the Rowett Research Institute, Aberdeen, were milked twice daily at approximately $08: 00$ and $16: 00 \mathrm{~h}$. They were fed a concentrate diet (500-1500 g/day depending on stage of lactation) with hay and water available ad libitum.

The NMR imager. The Aberdeen Mk I NMR imager operates at a magnetic field strength of $0.04 \mathrm{~T}$ (proton frequency of $1.7 \mathrm{MHz}$ ), and has a bore diameter of $49 \mathrm{~cm}$, which limits the size of goat that can be imaged to under $100 \mathrm{~kg}$. An interleaved saturation recovery/inversion recovery pulse sequence with a repetition time (Tr) of $1000 \mathrm{msec}$ and an interval (Ti) of $200 \mathrm{msec}$ was used. Transaxial slices $12 \mathrm{~mm}$ thick were collected through the body at $2-\mathrm{cm}$ intervals. From the data of each 4.3-min collection 2 fundamental image types were derived. Proton density (PD) images, which give information about the total proton spin populations (the amount of water and fat protons), were derived from the saturation recovery (SR) signal, while inversion recovery (IR) images, which contain PD information modified by the $T_{1}$ relaxation time, were derived from the IR signal. From these 2 basic image types the spin-lattice $\left(\mathrm{T}_{1}\right)$ relaxation time image was calculated. Other arithmetic combinations of the basic images are possible and one used in the present study was the difference image (D: PD - IR). On the Aberdeen system each image is displayed within $30 \mathrm{sec}$ of the end of each collection period, enabling decisions to be made concerning the positioning of the next image. Images were collected as $128 \times 128$ pixel grids, each pixel being a square equivalent to $0.352 \times 0.352 \mathrm{~cm}$. Therefore structures smaller than $5 \mathrm{~mm}$ were not resolvable.

Standard method for goat imaging. Before imaging, each goat was hand milked with the aid of exogenous oxytocin ( $200 \mathrm{mU}$ i.v.) and sedated using xylazine hydrochloride (Rompun; Bayer, Bury St Edmunds, Suffolk, UK), 0.012 mi/ $\mathrm{kg}$ i.v. The goat was placed on its left side on a sliding couch marked with a centimetre scale, and pushed into the imager. The posterior end of the udder was located using the couch scale and an image collected at that point. Images were then collected at 4-cm intervals by moving the goat in a posterior direction after each image. Once the anterior end of the udder was passed, images were staggered by $2 \mathrm{~cm}$ and then collected at $4-\mathrm{cm}$ intervals in the opposite direction. This process was continued until the entire anterior-posterior extent of the udder had been imaged at $2-\mathrm{cm}$ intervals.

Image analysis. Images were stored on movable magnetic hard discs with a capacity of approximately 12000 images. Analysis of the images was carried out using a MicroVax II minicomputer and image display hardware (advanced raster graphics system) running in-house image display software. During image analysis PD, D, IR and $\mathbf{T}_{1}$ images were displayed simultaneously (Fig. 1). The edge of the udder, mammary gland, or test object was outlined on the $\mathrm{D}$ image semi-automatically by the computer, and displayed on all 4 images. This process involves setting a threshold specific to mammary tissue or test object, the computer then fills all areas above the threshold. The computer-selected area is then 'trimmed' interactively, using a mouse which controls a display screen cursor, to conform to the outline of the mammary tissue or test object. Refinements, such as separating the 2 glands of the udder, were also carried out interactively. Fat surrounding the mammary gland was excluded interactively using the mammary tissue outline derived from the D image but displayed on the IR image. Blood vessels associated with mammary tissue were also excluded. Figure 2 shows an IR image with the different areas of mammary tissue outlined. Statistics from any particular region of interest, such as mean area $\left(\mathrm{cm}^{2}\right)$ and mean $T_{1}$ relaxation time (msec), were displayed on the user terminal.

The volumes (v) of the udders and test objects were calculated from serial transaxial images using slice areas (al, a2) from consecutive pairs of images with a separation (d) between slices, by means of a simple truncated cone model (Kvist et al., 1986):

$$
v=\Sigma d_{i} / 3 *\left[a 1_{i}+a 2_{i}\right]+\left(\sqrt{\left[a 1_{i}^{*} a 2_{i}\right]}\right)
$$

Accuracy of the method. Containers of simple or complex shape (plastic bottles, disposable surgical gloves) and $300-4500 \mathrm{ml}$ capacity were filled with dilute $\mathrm{CuSO}_{4}$ solution, to simulate the $\mathrm{T}_{1}$ characteristics of mammary tissues, and imaged with slice intervals of $2 \mathrm{~cm}$. An excised goat udder was imaged, also with a slice interval of $2 \mathrm{~cm}$. The volume of each of these test objects was calculated from the images as described above (i.e. using the D image) and then the calculation was repeated using each of the other 3 image types as the basis for deriving the cross-sectional information. The calculated volumes were compared with known volumes and weights. The complete analysis was performed 4 times to assess reproducibility. 

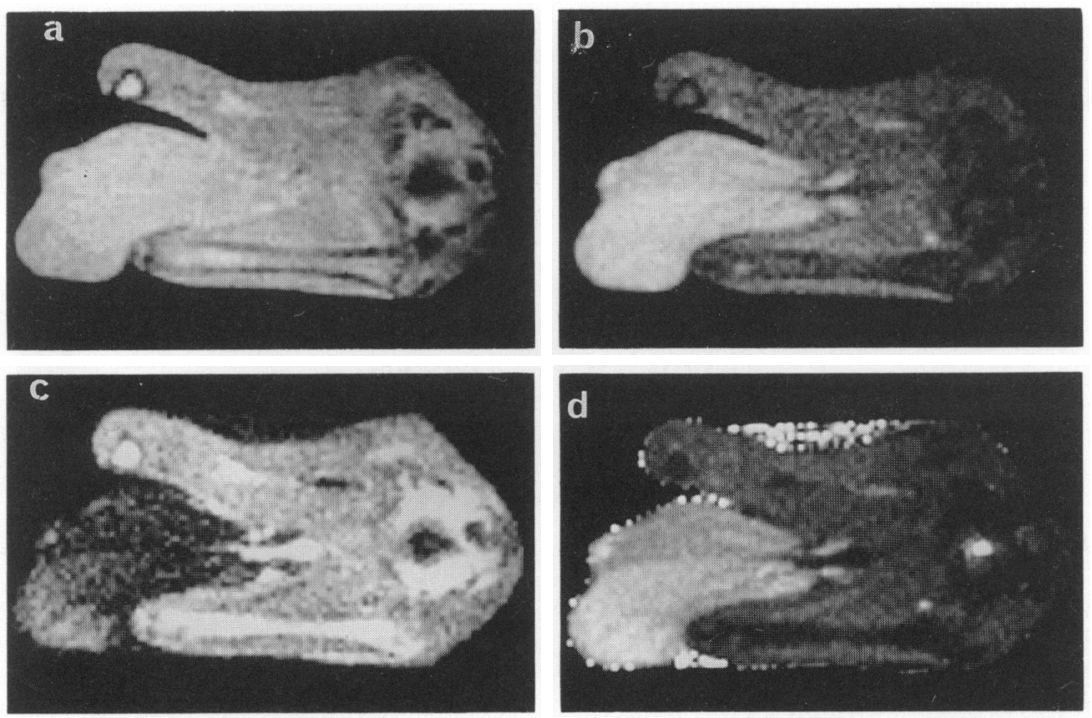

(e)

Right

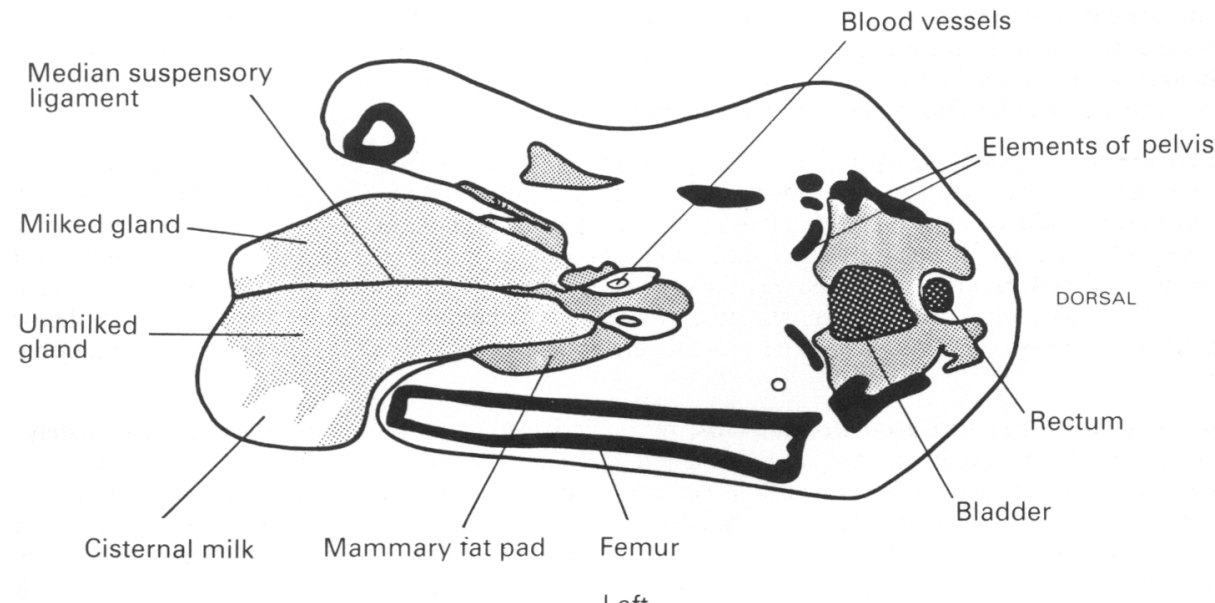

Left

Fig. 1. An example of the $4 \mathrm{MRI}$ image types used. All 4 images are versions of the same slice through a goat lying on its left side with only the right mammary gland milked-out before imaging: (a) PD image, (b) D image, (c) IR image, (d) $T_{1}$ relaxation time image: (e) labelled drawing illustrating the main features visible.

Using the standard procedure described, the volumes of the whole udder and each gland independently were calculated for 17 goats. Stage of lactation ranged from 15 to 30 weeks. Within 12 days after imaging, the goats were killed and the udders quickly excised, weighed (gross weight) and chilled on ice. All the skin, teat, gland cistern, major ducts, blood vessels and dissectable fat were trimmed away from the parenchyma, which was then weighed (parenchyma weight). The calculated volume (MRI) was compared with the gross and parenchyma weights, for the whole udder and also for each individual gland. In 10 of the goats udder volume was measured by water displacement $24 \mathrm{~h}$ before death, for comparison with MRI and in-vitro measurements.

Five goats were imaged twice on consecutive days. On the first occasion the standard procedure was used, but on the 2nd day milking was delayed until after imaging, whereupon the volume of milk removed was recorded. The two sets of images were thus of 'empty' and 'full' udders. During image analysis, fluid within the udder was identified and an estimate made of its volume; the difference in fluid volumes between the empty and full udders was then compared with the volume of milk removed at milking. 


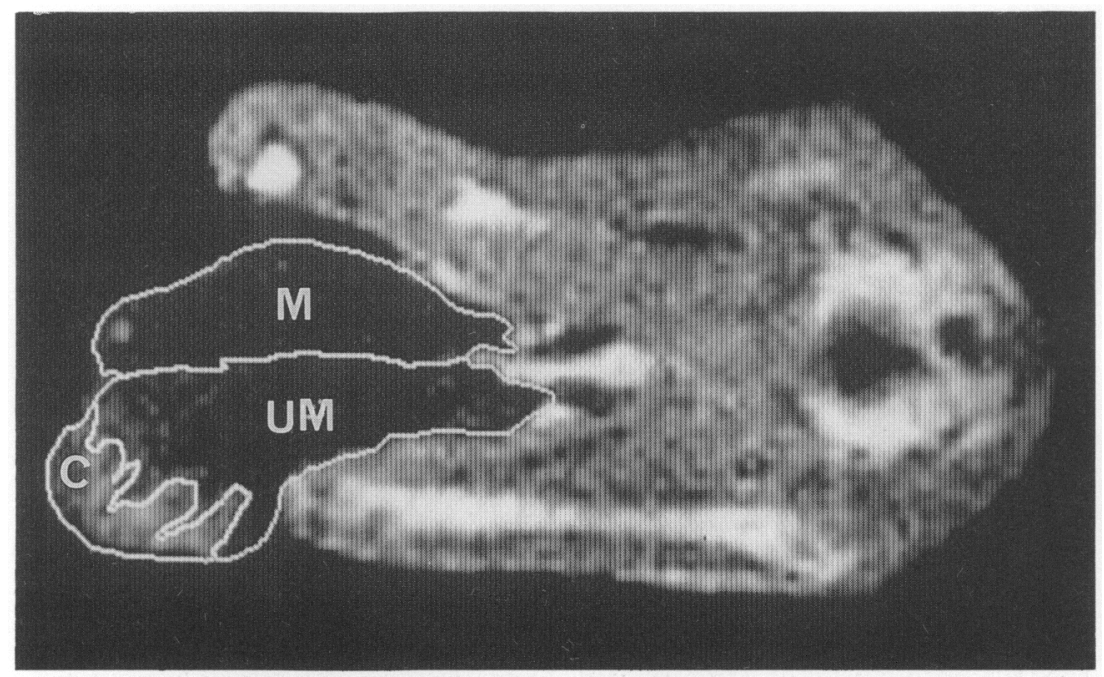

Fig. 2. An IR image through a goat lying on its left side. Both the milked (M) and unmilked (UM) glands, and the fluid within the unmilked gland (C) are shown outlined.

$T_{f}$ characteristics. Measurements of the $\mathrm{T}_{1}$ value of mammary parenchyma in vivo were compared with in-vitro determinations made within $4 \mathrm{~h}$ of death in 5 goats. The in-vitro measurements were made on small $(0.5-1 \mathrm{~g})$ samples of excised, blotted parenchyma in a home-built NMR relaxometer operating at $2.5 \mathrm{MHz}$ and $37^{\circ} \mathrm{C}$. A Hahn spin-echo pulse sequence with prior spin inversion was used with 15 different tau values to provide the relaxation curve. This was analysed assuming a single exponential decay by a three-point least-squares fit method. Each $\mathrm{T}_{1}$ relaxation value was the mean of 5 repeated measurements.

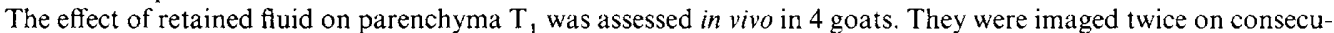
tive days, once after milking with oxytocin and once after milking by intraductal catheter (Henderson \& Peaker, 1987), which removes cisternal but not alveolar milk.

Statistical analysis. Statistical analysis was by analysis of variance (ANOVA) or paired $t$ test, as appropriate. Relationships between variables were tested by least-squared linear regression analysis, and correlation coefficients were determined. Values are presented as mean \pm s.e.m.

\section{Results}

\section{Test objects}

Errors in volume calculation were determined by subtracting the calculated from the known volume and expressing the result as a percentage of the latter. Taking all test objects together, error varied from $-4 \cdot 3 \pm 2 \cdot 7 \%$ to $+3 \cdot 5 \pm 2 \cdot 9 \%$, depending on which image type was used, although none of the determinations was significantly different from each other or from the actual volume of the test object. The error obtained with simple shapes $(+0 \cdot 3 \pm 4 \cdot 2 \%)$ was not significantly less than that obtained with complex ones $(-3.3 \pm 5.0 \%$ for the excised udder). Increasing the slice interval from $2 \mathrm{~cm}$ to $4 \mathrm{~cm}$ increased the error non-significantly $(-2 \cdot 7 \pm 0.9 \%$ to $-5 \cdot 1 \pm 4 \cdot 7 \%)$. Repeated determinations on the same test object yielded a range of errors between $-2 \cdot 1 \pm 6 \cdot 4 \%$ and $+0 \cdot 1 \pm 2 \cdot 6 \%$.

There was a linear and proportional relationship between MRI-calculated and known volumes of test objects, within the range $300-4500 \mathrm{ml}$ (Fig. 3). Least-squares linear regression of MRI calculated on known volumes yielded a slope of 1 with an intercept offset of $10.7 \mathrm{ml}$. The total error of

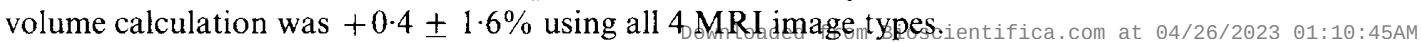




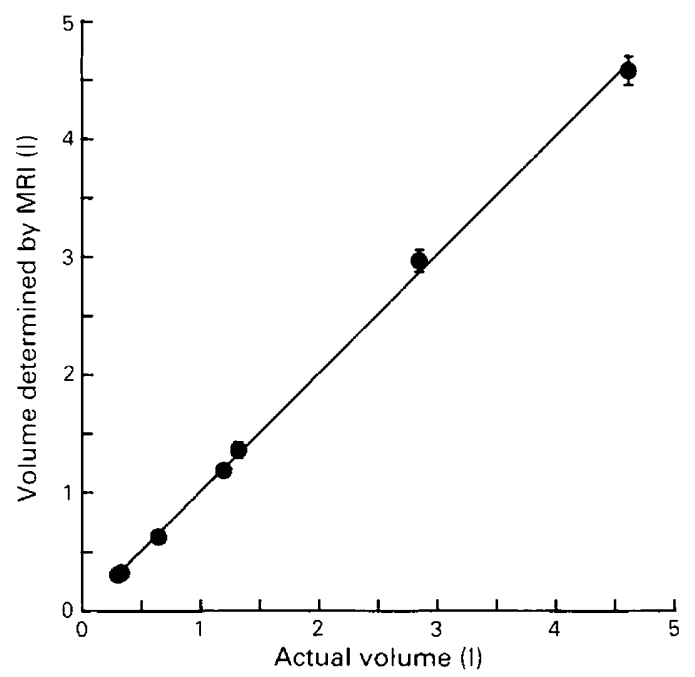

Fig. 3. The relationship between MRI-calculated and measured volumes of test objects.

\section{In-vivo volume determinations}

Using the standard method, imaging time was between 50 and $65 \mathrm{~min} /$ goat, depending upon the size of the udder. Occasionally (4\% of imaging sessions) sedation was of insufficient duration to allow complete collection of all $2 \mathrm{~cm}$ slices, and then volume calculation was based on $4 \mathrm{~cm}$ slices. The udder of the goat was most clearly delineated in the D image. Discrimination between parenchyma and fatty stroma was best achieved in the IR image, and the $T_{1}$ image was used for identifying fluid within the udder. Figures 1 and 2 show the udder of a lactating goat with one unmilked gland and one milked gland. The whole udder, the individual glands and the fluid present in the unmilked gland have been outlined in Fig. 2.

The estimate of mammary volume produced by MRI for the 17 lactating goats was $1696 \pm 100 \mathrm{ml}$; the measured gross weight was $1892 \pm 116 \mathrm{~g}$, and the parenchyma weight was $1103 \pm 101 \mathrm{~g}$. Overall, MRI underestimated gross weight by $10.4 \%$ and overestimated parenchyma weight by $53.8 \%$. Linear regression analysis demonstrated highly significant correlations between MRI estimates and both gross and parenchyma weights:

$$
\text { MRI estimate }=294+0.741 \times \text { gross weight }\left(r=0.87, P<0 \cdot 001, \mathbf{R}^{2}=75 \cdot 0 \%\right)
$$

$$
\text { MRI estimate }=735+0.871 \times \text { parenchyma weight }\left(r=0.88, P<0.001, \mathrm{R}^{2}=76.1 \%\right)
$$

The parenchyma weight relationship is shown in Fig. 4.

Udder volume was determined by water displacement in 10 goats. Correlations with parenchyma weight were $0.86(P<0.001)$ for MRI and $0.83,(P<0.001)$ for water displacement. These data were heavily influenced by the exceptionally large udder of one goat. Excluding this datum point resulted in correlations of $0.80(P<0.001, \mathrm{MRI})$ and 0.09 (n.s., water displacement). The parenchymal portion of the udder ranged from $48 \%$ to $69 \%$ of gross mammary weight in the 10 goats. Ranking into 2 groups of 'highest' $(65.5 \pm 1 \cdot 3 \%)$ and 'lowest' $(53.6 \pm 1 \cdot 7 \%)$ parenchymal content produced groups with significantly different parenchymal mass $(1496 \pm 221$ versus $965 \pm 64 \mathrm{~g}, P<0.05)$ and MRI estimated volumes $(2077 \pm 185$ versus $1404 \pm 141 \mathrm{ml}, P<0.05)$, but similar udder volumes by water displacement $(2049 \pm 266$ versus $1837 \pm 101$, n.s.).

Estimates of individual gland size by MRI were also highly correlated with both the gross weight $(r=0.91, P<0.001)$ and the weight of parenchyma $(r=0.85, P<0.001)$ of the individual 


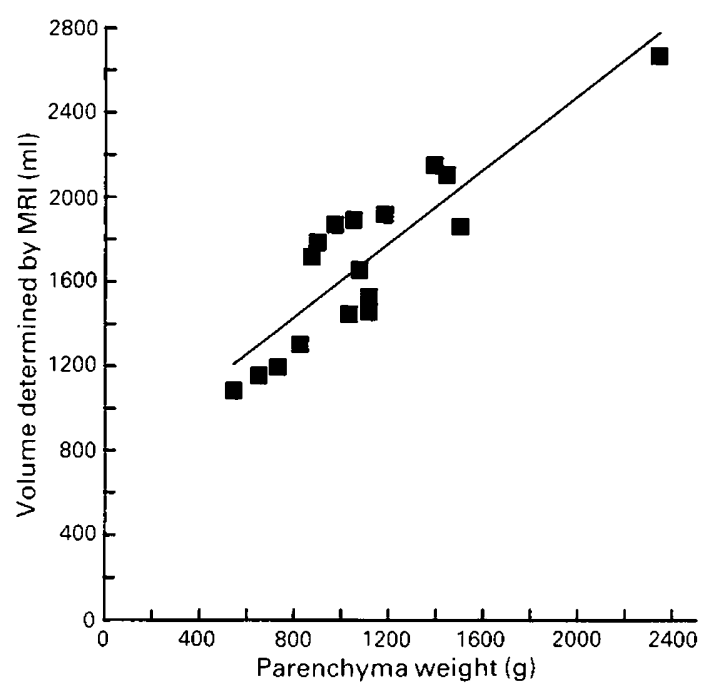

Fig. 4. The relationship between the MRI estimate of parenchyma volume and the actual weight of parenchyma determined post mortem for a group of 17 goats.

glands. In 15 of 17 goats MRI correctly identified the larger of the two glands. Overall, the ratio between the right and left glands was $0.92 \pm 0.06$ by parenchymal weight and $0.97 \pm 0.05$ by MRI; the two determinations were not significantly different from each other.

The volume of fluid retained in the udders of 4 goats was $103 \pm 48 \mathrm{ml}$ when they were milked before imaging (empty udder) and $623 \pm 128 \mathrm{ml}$ when they were milked after imaging (full udder), a difference of $521 \pm 102 \mathrm{ml}$. This estimate of removable milk agreed almost exactly with the volume of milk subsequently removed from the full glands $(515 \pm 101 \mathrm{ml})$.

\section{$\mathbf{T}_{1}$ characteristics}

In-vivo determinations of $T_{1}$ relaxation time from regions consisting primarily of parenchyma were not significantly different from in-vitro measurements of parenchyma $T_{1}(269 \pm 18$ versus $263 \pm 29 \mathrm{msec}$ ). The overall $T_{1}$ value for the whole udder was considerably greater for unmilked glands than for those which had been milked (449 \pm 37 versus $272 \pm 10 \mathrm{msec}, P<0.001, t$ test). Prior milking with oxytocin reduced the in-vivo parenchyma $T_{1}$ estimate compared to that obtained when the gland cistern was emptied by catheter but alveolar milk was retained $(260 \pm 3$ versus $287 \pm 7 \mathrm{msec}, P<0.05, t$ test). The correlation between whole-udder $\mathrm{T}_{1}$ and fluid content of the gland was high $(r=0.98, P<0.001)$.

\section{Discussion}

Previous studies of mammary development have been limited to external examination, postmortem analysis or biopsy (Knight, 1984). Measurement of udder volume by Archimedes' principle of water displacement (Linzell, 1966) is useful for comparing udders of relatively similar composition, but the present results demonstrate that parenchymal content does vary between goats (even during lactation) and erroneous conclusions can result. Plaster casts (Ingelby, 1949) and wire-mesh modelling (Junge, 1963) suffer from the same limitation, i.e. they determine only gross volume. An imaging technique is required if the relative content and absolute amount of parenchyma is to be determined in vivo. 
Sørensen et al. (1987) explored the use of X-ray CT for quantitative analysis of the excised udders of heifers, which consist of relatively small amounts of ductal parenchyma lying within a large fat pad, i.e. the parenchyma content is small and rather variable. The CT estimate of parenchyma volume was considerably lower than the weight of dissected parenchyma, but very similar to the calculated weight of 'true' parenchyma, based on histological analysis of the dissected tissue. It was concluded that CT excluded extra-parenchymal tissue (chiefly fat) more reliably than did physical dissection. CT has not been used to study mammary tissue in vivo, but has been used for in-vivo whole-body analysis of goats, pigs and sheep (see Foster et al., 1988, for review).

We have previously reported preliminary data obtained with MRI on mammogenesis in goats (Foster \& Knight, 1983; Fowler et al., 1988). The present results indicate that the straightforward determination of volume using MRI is accurate and reproducible; test objects were measured with an error of 1-2\%. Estimation of mammary parenchyma in vivo is less precise, because of the additional requirement of first differentiating between parenchyma, mammary stroma and the rest of the body. The fact that the MRI estimate fell between the gross weight and the parenchyma weight indicates that some but not all of the extraparenchymal tissue was excluded from the calculation. The excellent correlation between the MRI estimate of parenchyma volume and the actual weight of parenchyma suggests that the method is reliable. Most importantly, MRI correctly predicted differences in the absolute amount of parenchyma which were due to variation in the composition of the udder. These compositional differences were small in comparison to the changes which occur during the gestational development of the gland, and so it is highly probable that MRI would correctly identify these latter changes as well.

In the present study, structures smaller than $5 \mathrm{~mm}$ were not resolvable in the images. This places the median suspensory ligament which divides the two mammary glands of the goat at the very limit of resolution. Nevertheless, visual discrimination between the two individual glands was possible in the majority of images, and by cross-referring between adjacent images ( 16 images can be displayed simultaneously) it was possible to identify reliably the mid-line in all images. MRI is therefore able to measure individual glands in vivo, a vital consideration in experiments investigating local control mechanisms, in which treatment is applied unilaterally to one gland only.

The relationship between intramammary fluid and mammary $T_{1}$ was expected, given that tissue water affects $T_{1}$ relaxation rates (Foster \& Hutchison, 1985). Thus whole-udder $T_{1}$ was greater in unmilked glands than milked ones, and parenchyma $T_{1}$ was reduced by the milk-ejecting effect of oxytocin.

MRI is essentially a clinical diagnostic tool, and has been used for a variety of applications, including study of the human breast (El Yousef et al., 1984). Foster et al. (1988) have reviewed potential research applications of MRI in the area of whole-body compositional analysis. The present results indicate that the technique will also be useful for studying the development of individual tissues, in this case the mammary gland. It enables accurate estimates of parenchyma volume to be made repeatedly in individual animals, thus allowing serial study through the course of reproductive cycles or treatment periods.

This study was funded by AFRC Link-group grant no. LRG23. We thank Mr I. Brown for invaluable assistance throughout the study; Mrs L. L. Hutcheon for help with data analysis; and Dr A. Law and Mr P. Ross for their contribution to the image analysis.

\section{References}

El Yousef, S.J., Duchesneau, R.H., Alfidi, R.J., Haaga, J.R., Bryan, P.J. \& LiPuma, J.P. (1984) Magnetic resonance imaging of the breast. Radiology 150 , $761-766$.

Foster, M.A. \& Hutchison, J.M.S. (1985) NMR imaging-method and applications. J. Biomed. Eng. $7,171-182$.
Foster, M.A. \& Knight, C.H. (1983) Nuclear magnetic resonance (NMR) imaging: a non-invasive technique for measuring mammary gland development. $J$. Physiol., Lond. 341, 82P, abstr.

Foster, M.A., Fowler, P.A., Fuller, M.F. \& Knight, C.H. (1988) Non-invasive methods for assessment of body composition. Proc. Nutr. Soc. 47, 375-385, 
Fowler, P.A., Knight, C.H. \& Foster, M.A. (1988) Magnetic Resonance Imaging (MRI) studies of udder development and milk production in primiand multi-parous goats. J. Reprod. Fert., Abstr. Ser. 1, Abstr. 35.

Henderson, A.J. \& Peaker, M. (1987) Effects of removing milk from the mammary ducts and alveoli, or of diluting stored milk on the rate of milk secretion in the goat. Q. Jl exp. Physiol. 72, 13-19.

Hutchison, J.M.S., Edelstein, W.A. \& Johnson, G. (1980) A whole-body NMR imaging machine. J. Phys. E: Sci. Instrum. 13, 947-955.

Ingelby, H. (1949) Changes in breast volume in a group of normal young women. Bull. Intern. Assoc. Med. Mus. 29, 87-94.

Junge, F. (1963) Volumenmessungen am euter derziege and ihre beziehungen zur milchleistung. Inaug. Dissertation, Ludwige-Maximilians University, Munich.
Knight, C.H. (1984) Mammary growth and development: strategies of animals and investigators. Symp. zool. Soc. Lond. 51, 147-170.

Kvist, H., Sjostrom, L. \& Tylen, U. (1986) Adipose tissue volume determinations in women by computed tomography: technical considerations. Int. J. Obesity 10, 53-67.

Linzell, J.L. (1966) Measurement of udder volume in live goats as an index of mammary growth and function. J. Dairy Sci. 49, 307-311.

Sejrsen, K., Foldager, J. Sørensen, M.T., Akers, R.M. \& Bauman, D.E. (1986) Effect of exogenous bovine somatotrophin on pubertal mammary development in heifers. J. Dairy Sci. 69, 1528-1533.

Serensen, M.T., Serjrsen, K. \& Foldager, J. (1987) Estimation of pubertal mammary development in heifers by computed tomography. J. Dairy Sci. 70, 265-270.

Received 10 August 1989 